\title{
SOME NEW IDEAS IN NUMERICAL APPROACH TO THERMAL NON DESTRUCTIVE TESTING PROBLEMS
}

\section{Ivanka Boras, Srećko Švaić}

\author{
Faculty of Mechanical Engineering and Naval Architecture \\ University of Zagreb \\ Ivana Lučića 5,10 000 Zagreb, Croatia
}

\begin{abstract}
The paper presents the results of the research carried out on two samples made of different material by means of transient thermography.

One sample is made of phenoxy resin and another one of phenoxy resin reinforced with cooper fibers.

The experiments have been done together with numerical simulation. The goal of the research was to find the possibility of using numerical simulation for prediction of the results before starting with real experiment. Namely numerical analysis enable one to simulate a set of experiments on the computer and to select the proper parameters for real one. The further advantage of the numeric is a possibility for observing the temperature fields on various planes inside the sample.
\end{abstract}

\section{INTRODUCTION}

Numerical approach in detection and quantification of the subsurface defects in TNDT gives a significant results in confirmation of the basic parameters of the defect characteristic such as maximal contrast and maximal contrast of the contrast curve versus time.

The numerical simulation of a heat transfer through the object with the subsurface defect is based on the application of the control volume method combined with the inverse method. It has been carried out with the aim to find the possibility of making software, which will enable the correct description of the internal structure of the sample. For that the start and boundary conditions, as well as the geometrical characteristic of the sample and the defects must be known.

In the work presented two models having the same shape but made of different materials were analyzed. The results were used to predict the behavior of the sample made of the mixture of both materials.

\section{SAMPLES}

The samples are shown on fig. 1 (phenoxy resin) and fig. 2 (phenoxy resin with cooper fibers). The defects have the form of the grave.

\section{EXPERIMENTAL RIG}

All the measurements were carried out on the experimental rig shown on fig. 3 . The temperature distribution on the object surface has been monitoring and recorded by means of the IR camera AGEMA 570 PRO. The observed object was heated with $0.5 \mathrm{~kW}$ IR heater. Duration of the heating was registered and the temperatures controlled with the thermocouples in the referent points and later compared with the numerically obtained results. 


\section{EXPERIMENTS}

The experimental part of the research has been carried out on the samples made of both materials, pure phenoxy resin and phenoxy resin reinforced with cooper fibers. The parameters such as a value of the heat flux and heating time were varied to find the parameters, which will suit the configuration of the models and show the influence of added material.

For the sample made of phenoxy resin the heating time of 5-min gives temperature differences on observing plane high enough for defect determination. For the sample made of phenoxy resin with cooper fibers the heating time was longer, approximately $10 \mathrm{~min}$. That sample has the bigger defects, which are closer to the surface. Such result has been expected according to the results from simulation.

Thermograms of the both samples are given on figure 4 and 5 . For the sample made of phenoxy resin-cooper mixture the temperature distribution on the surface is more uniform, but some colder spots appear. That can be the consequence of different cooper particle distribution in base material.

\section{NUMERICAL SIMULATION}

Numerical procedure is based on the control volume method and 3D non-stationary heat conduction. The control volume net is adjusted according to the temperature gradients. Total number of control volumes is $32 \times 37 \times 14$ which dimensions varied from 1 to $10 \mathrm{~mm}$. The time step depends on the sample material properties and vary from 0.02 to $0.2 \mathrm{~s}$. The properties for sample materials are: phenoxy resin: $\lambda=0.3 \mathrm{~W} /(\mathrm{mK}), \rho=1600 \mathrm{~kg} / \mathrm{m}^{3}, c=1300 \mathrm{~J} /(\mathrm{kgK})$; cooper: $\lambda=372 \mathrm{~W} /(\mathrm{mK}), \rho=8300 \mathrm{~kg} / \mathrm{m}^{3}, c=383 \mathrm{~J} /(\mathrm{kgK})$. In the phenoxy resin - cooper mixture the percent of the cooper is about $15 \%$ which distribution is supposed to be uniform.

The results of numerical simulation for samples made of different materials having same geometry (fig 1.) are given on figure 6 (real model), 7 and 8.

On figure 9 are presented numerically predicted results for sample (real model) made of phenoxy resin with cooper fibers (fig 2.).

\section{CONCLUSION}

The paper presents the procedure for predicting the behavior of the sample made as a composite which characteristic has been found by superposition. The simulation carried out gives the optimistic results. For better results the real characteristic of the sample material must be known. The non-homogeneity of the material gives inaccurate information about subsurface defect and their geometry. On figures 10,11, 12 and 13 the comparison of the measured and calculated temperature distribution on the sample surface is given for the spots lined on the fig 8 and 9.

The influence of the cooper particles in sample can be seen as a higher temperature level for the same energy input.

\section{LITERATURE}

[1] S.V. PATANKAR, Numerical Heat Transfer and Fluid Flow, Hemisphere Publishing Corporation, Mc Grow-Hill Book Co, Washington, (1980)

[2] D.P. ALMOND, P.M.PATEL, Photothermal Science and Technique, London, Chapman \& Hall, (1996)

[3] Anderson D.A., Tannehill J.C., Pletcher R.H., Computational Fluid Mechanics and Heat Transfer, Hemisphere Publishing Corporation, Washington, USA, 1984. 
[4] I. BORAS, S.ŠVAIĆ, A.GALOVIĆ, Mathematical model for simulation of defects under material surface applied to thermographic measurements, Quantitative Infrared Thermography, QIRT 98, Lodz, Poland, 12-15 (1998)

[5] MINKOWYCZ W.J., SPARROW E.M., SCHNEIDER G.E., PLETCHER R.H., Handbook of Numerical Heat Transfer, John Wiley \& Sons Inc., New York, 1988.

[6] CHAPMAN A.J., Heat Transfer, Macmillan Publishing Company, New York, (1984)

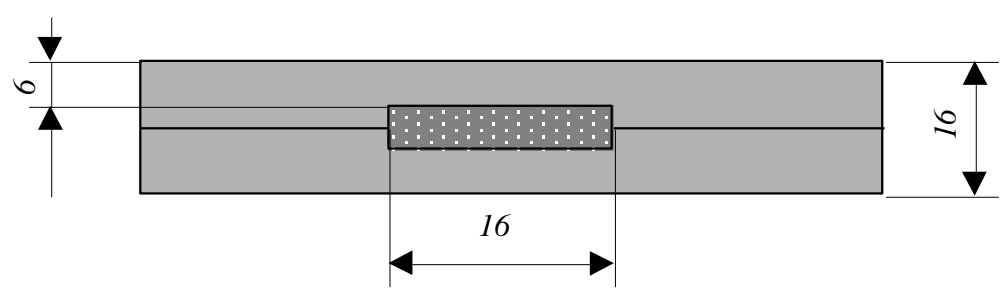

Figure 1 The cross section of sample made of phenoxy resin

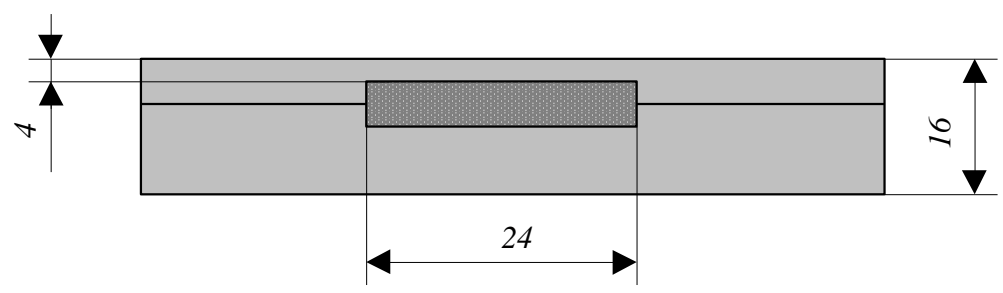

Figure 2 The cross section of sample made of phenoxy resin with cooper fibers

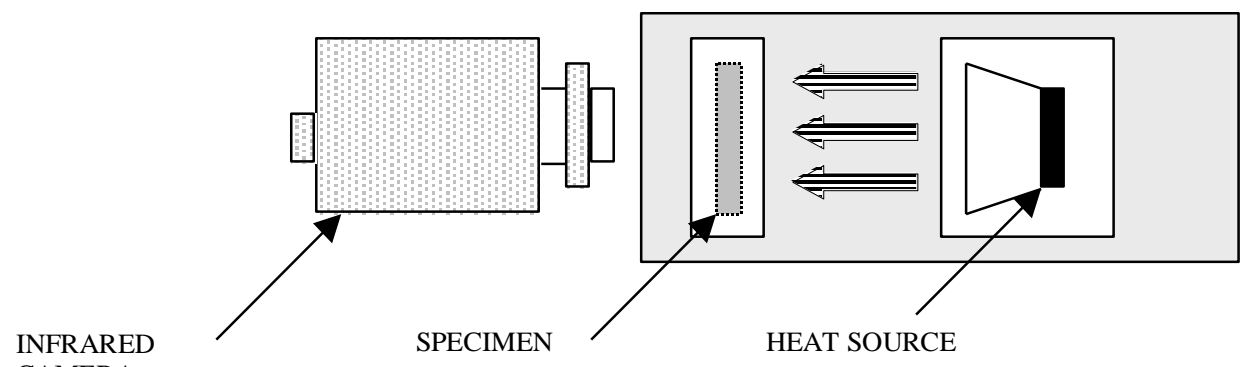

Figure 3 The experimental rig 


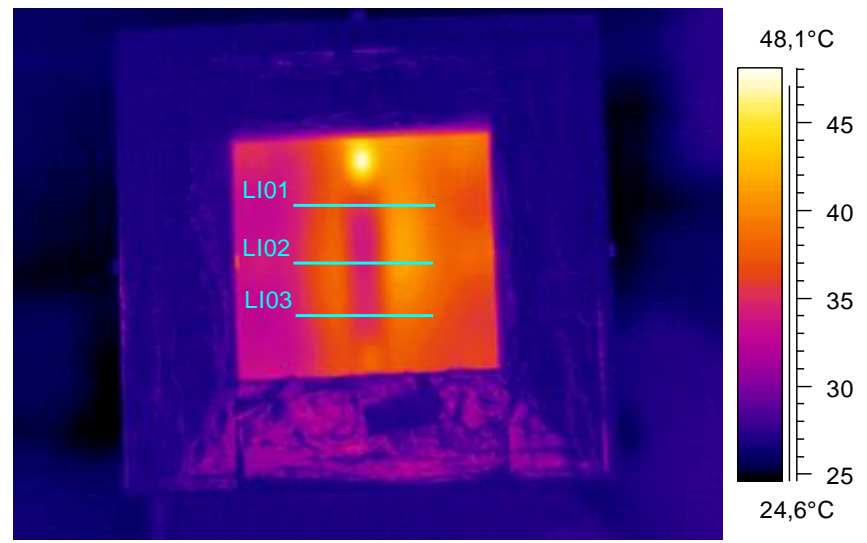

Figure 4 The experimental result for sample made of phenoxy resin, $t=300 \mathrm{~s}$
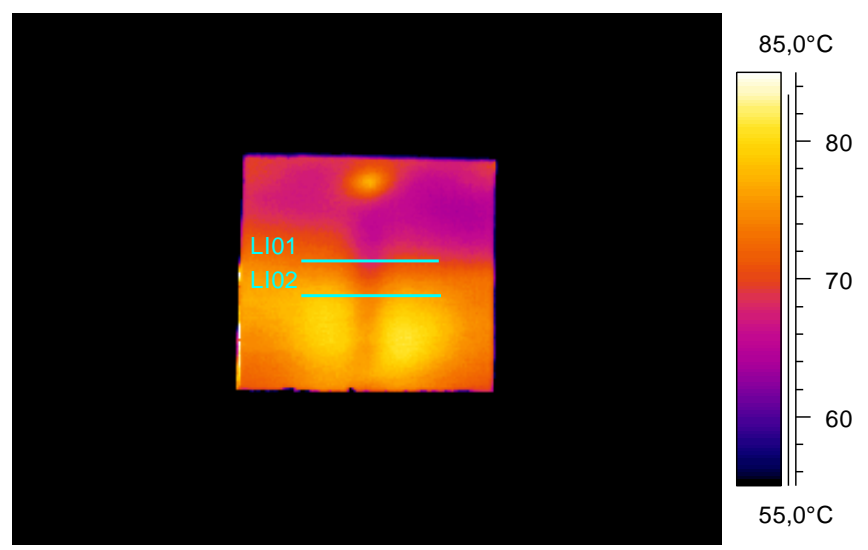

Figure 5 The experimental result for sample made of phenoxy resin with cooper fibers, $t=600 \mathrm{~s}$

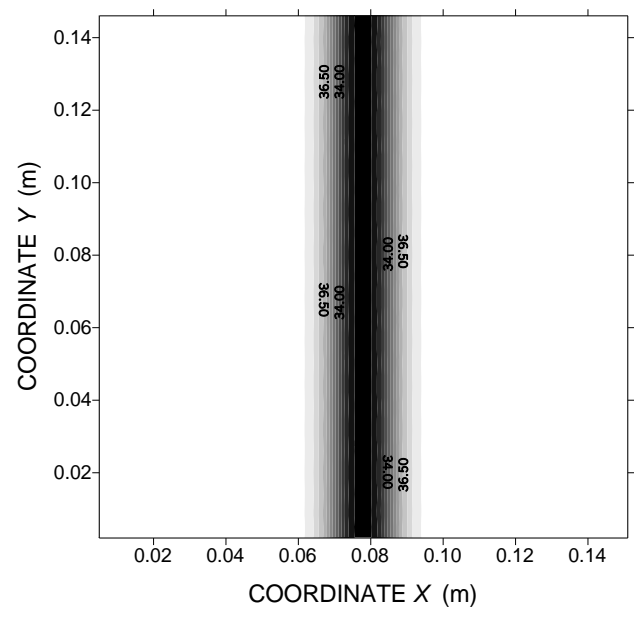

Figure 6 The result of numerical simulation for sample made of phenoxy resin (real model), $t=300 \mathrm{~s}$

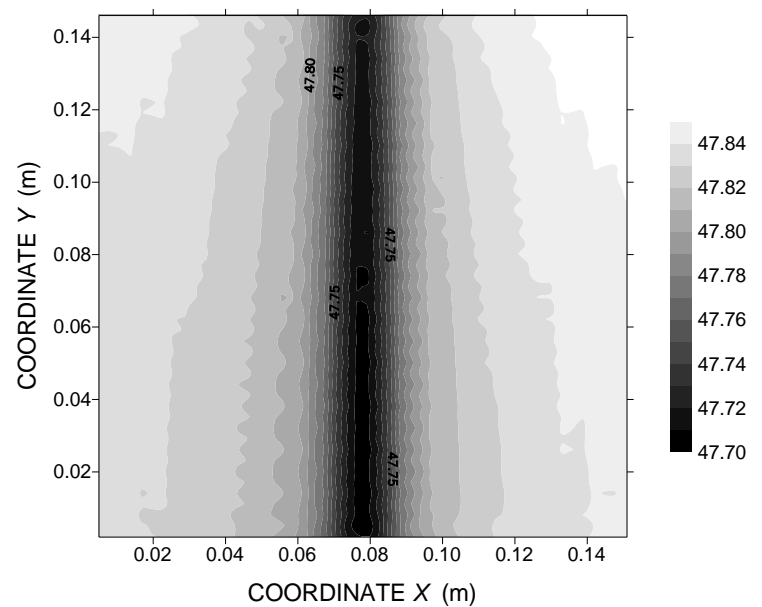

Figure 7 The result of numerical simulation for sample made of cooper, $t=300 \mathrm{~s}$ 


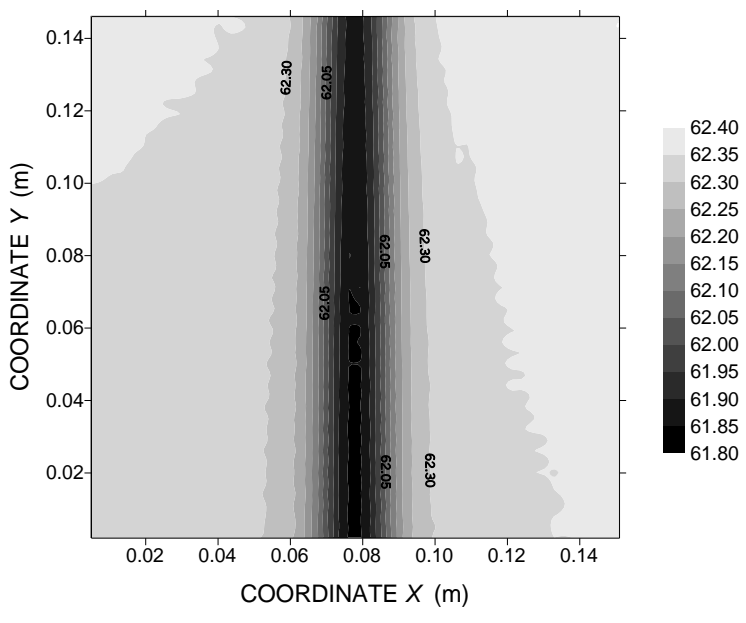

Figure 8 The result of numerical simulation for sample made phenoxy resin with cooper fibers, $t=300 \mathrm{~s}$

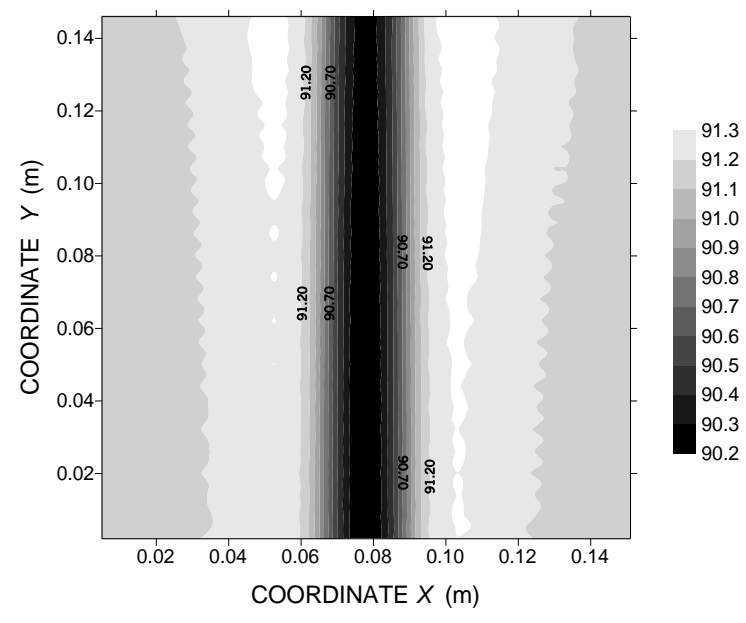

Figure 9 Numerical prediction of temperature distribution for sample made of phenoxy resin with cooper fibers for real model, $t=600 \mathrm{~s}$

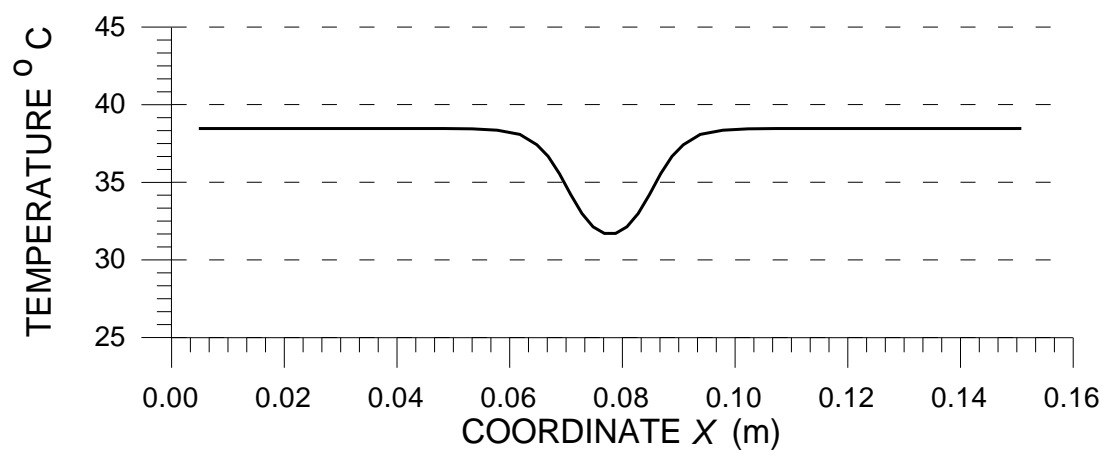

Figure 10 Numerical result of temperature distribution, $y=0.078 \mathrm{~m}$, phenoxy resin, $t=300 \mathrm{~s}$

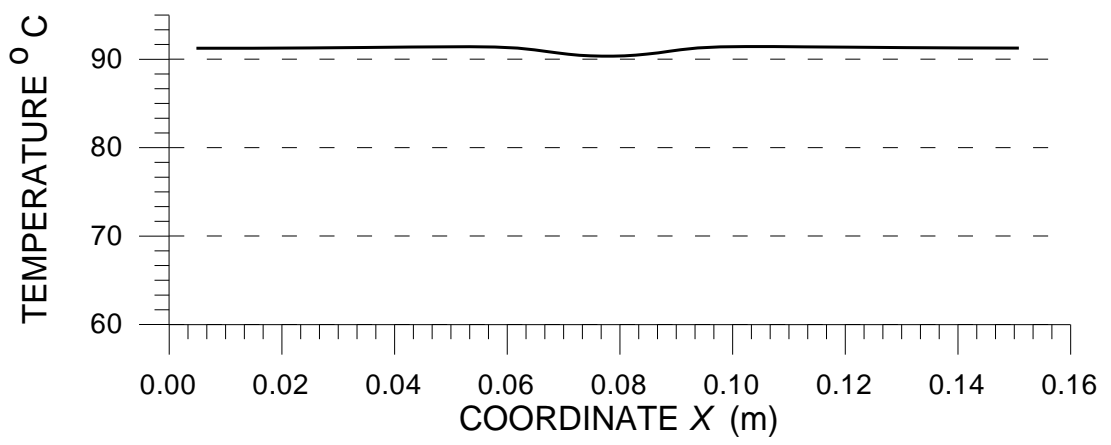

Figure 11 Numerical result of temperature distribution, $y=0.078 \mathrm{~m}$, phenoxy resin with cooper fibers, $t=600$ 
http://dx.doi.org/10.21611/qirt.2000.038

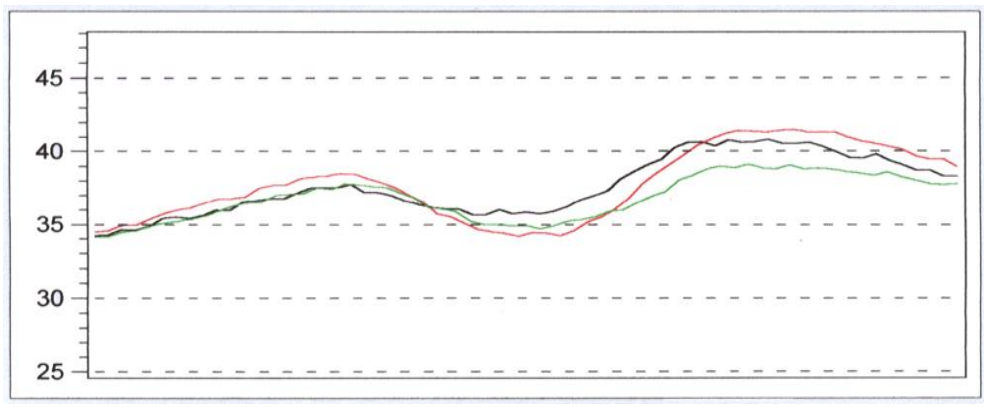

Figure 12 Experimental results of temperature distribution, phenoxy resin, $t=300 \mathrm{~s}$ (for lines shown on figure 4)

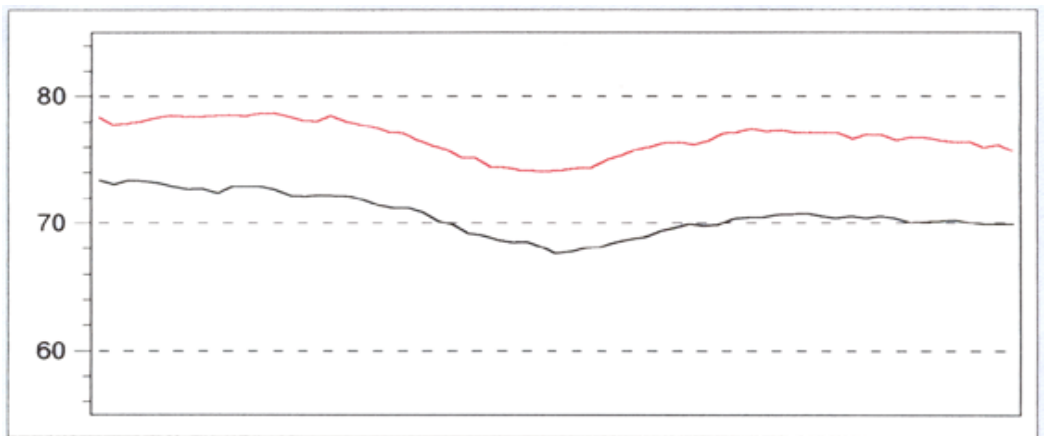

Figure 13 Experimental results of temperature distribution, phenoxy resin with cooper fibers, $t=600 \mathrm{~s}$ (for lines shown on figure 5) 